\title{
CMA launches social networking site
}

Early released Aug. 20, 2008

A

11 medical students, residents and practising doctors in Canada will have access to a new Facebook-style social networking site launched by the Canadian Medical Association (CMA).

To access the physician-only interactive network, called Asklepios, doctors need not be CMA members, but do need to register at www.cma.ca using the identification numbers CMA provides to every medical student and doctor in the country. Delegates to the CMA's 141st annual general council were given a sneak preview of the innovative site on Aug. 19, 2008 during CMA General Council in Montréal, Quebec.

Asklepios will allow for both social networking and professional information sharing, says Dr. Jay Mercer, a family doctor and the medical director for Practice Solutions Web Services Inc., an Ottawa-based firm that provides technology and practice management systems for physicians.

Anonymous participants will not be permitted to use the site, which should allow it to be largely member-run without the need for oversight, he said.

Mercer, who posted a query on the site about a medical matter and received useful information from a specialist, said he expected the site would be particularly useful for students and residents. He also expects groups to form on the site based on shared interests and circumstances allowing, for example, rural doctors, general practice psychotherapists or doctors with the Canadian military, to share information and expertise. "Doctors will control the way the thing goes," he said, noting that interest has already been expressed in including blogs from doctors on the site.

Other medical associations in Canada operate online discussion forums, but the sites are not as sophisticated, he said. It should be widely accessible since more than $95 \%$ of Canadian doctors use the Internet.

In a trial run of the site, 100 doctors were invited to participate, but their numbers quickly doubled because of the option to invite friends and colleagues on board, Mercer said.

Although non-CMA members can join the site, they won't have access to some of the members-only resources such as MD Consult, which provides access to textbooks, journals, CMA library services and answers to medical queries. - Ann Silversides, CMAJ

CMAJ 2009. DOI:10.1503/cmaj.081315 